\title{
Die Schöpfung der Schmetterlinge
}

\section{Iris Ritzmann}

Prof. Dr. med. et lic. phil., Mitglied der Redaktion Medizingeschichte

Der Kupferstich ist von seltener Plastizität. Schmetterlinge in voller Lebensgrösse bewegen sich auf dem Bildrahmen. Sie schweben gleichsam über ihn hinaus, zwischen dem Betrachter und dem eigentlichen Bild. iris.ritzmann[at]saez.ch

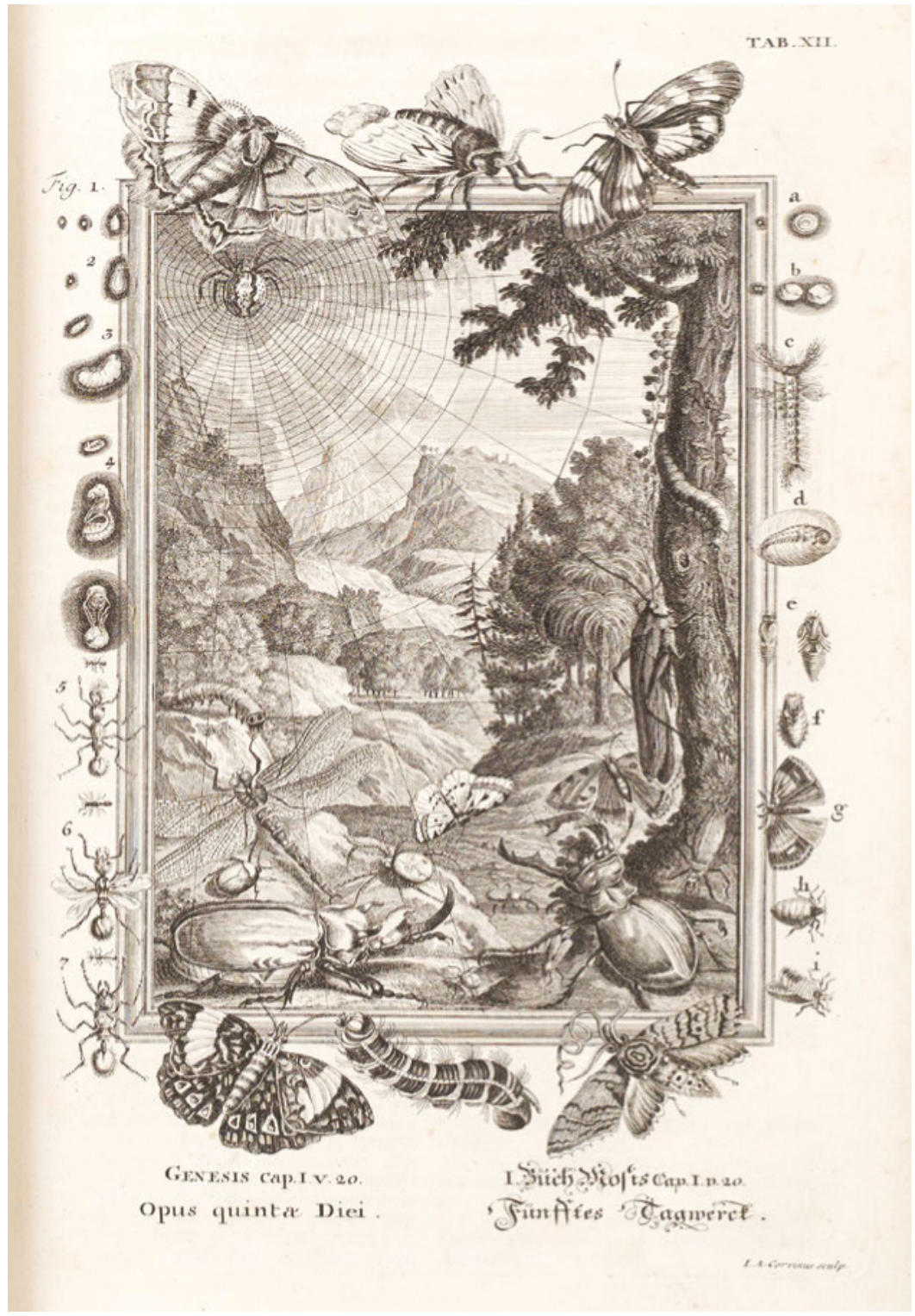

KupfertafeI XII zur naturkundlichen Illustration zur Erschaffung der Insekten am fünften Schöpfungstag, aus Johann Jacob Scheuchzer: Kupfer-Bibel oder Physica Sacra, Augsburg und UIm, bei Johann Andreas Pfeffel, 1731-1735.
Ein Spinnennetz gibt wie ein Theatervorhang den Blick auf die Bühne der eigentlichen Szene frei: den fünften Tag der Schöpfung. Die Insekten stehen aber nur am Anfang einer ganzen Serie von Stichen über die Erschaffung der Tierwelt.

Der Kupferstich findet sich im Lebenswerk des Zürcher Stadtarztes Johann Jacob Scheuchzer (1672-1733), das den Titel Kupfer-Bibel oder Physica sacra trägt und in den Jahren 1731 bis 1735 in Augsburg erschienen ist. Mit den vier voluminösen Bildbänden wollte der fromme Scheuchzer die Existenz Gottes mit naturkundlichen Beobachtungen beweisen. Er arbeitete sich von Bibelzitat zu Bibelzitat und bebilderte jedes Thema mit Kupferstichen. Hierfür engagierte Scheuchzer mehrere Künstler, die nach seinen Vorgaben 750 grossformatige Tafeln schufen.

Einzelne Details auf den Stichen stammen aus anderen, damals bekannten naturkundlichen Werken. Die Entwicklung der Ameise am Rand des Insektenbildes ist beispielsweise Jan Swammerdams Historia Insectorum Generalis von 1669 entnommen; desgleichen die Entwicklung des Falters, vom Ei bis zum geflügelten Insekt. Aber woher stammen die Schmetterlinge? Für die wunderbare Verwandlung des «Sommer-Vogels» griff der Kupferstecher zu einem bereits zu Scheuchzers Lebzeiten sehr kostbaren und seltenen Bildband: Maria Sibylla Merians Buch über die Insektenwelt in Surinam von 1705, das durch die Expedition der Naturwissenschaftlerin und Künstlerin in die berüchtigte südamerikanische Sklavenkolonie möglich geworden war. Merian wurde so zur Schöpferin von mehreren Schmetterlingen und Raupen in Scheuchzers Werk. Scheuchzers imposanter Vierbänder kann im Museum für Medizinhistorische Bücher Muri bewundert und digital erkundet werden. Auch Merians prächtiges Surinam-Buch ist dort in der Wechselausstellung «Schmetterlinge und Leidenschaft - Maria Sibylla Merians Lebenswerk" zu sehen. Diese Konstellation verleiht der Schöpfung der Schmetterlinge in der Kupfer-Bibel eine neue, ganz profane Deutung.

Bildnachweis

Museum für medizinhistorische Bücher Muri (mmbm.ch) 